The Adjourned Menting of the Members was held in the Lecture Theatre of the Mechanics' Institution, David Street, Manchester, on Thursday, June 25th, 1857; Joseph Whitworth, Esq., President, in the Chair.

The following Paper, by the President, was read :-

\title{
ON A STANDARD DECIMAL MEASURE OF LENGTH FOR MECHANICAL ENGINEERING WORK, \&c.
}

In the address which $I$ had the honour of delivering before the Members of this Institntion at the Glasgow Meeting last year, I briefly alluded to the beneficial results which would follow the application of the decimal system to our weights and measures, referring more particularly to the latter. In compliance with the wish expressed by several members of the Council, I propose in the present paper to bring this important subject more prominently under the notice of the members, confining myself however to its practical bearing on mechanical operations, without discussing different systems of notation, which I leave to other and abler hands.

I have long been convinced that great and rapid progress would be made in many branches of the mechanical arts, if the decimal system of measures could be generally introduced. To state the case broadly, instead 
of our engineers and machinists thinking in eighths, sixteenths, and thirtyseconds of an inch, it is desirable that they should think and speak in tenths, hundredths, and thousandths. I can assure those who have been accustomed to the fractional system that the change to the more perfect decimal one is easy of attainment, and, when once made, it will from its usefulness and convenience amply repay any trouble which may have attended its acquirement. In the manufacture of my standard gauges of size, the workmen measure to the 1-20,000th of an inch, and these measures are as farniliar and appreciable as those of any larger dimensions. It will therefore be at once conceded that the only scale of measurement which can be used for such small sizes and proportionally small differences must be a decimal one, as any other would be productive of insurmountable difficulty, if not of utter confusion.

When the sizes of the fitting parts of machines are determined by sight from the lines on a scale or a two-foot rule, such nicety of measurement is out of the question; and as long as they are made on that system, the progress of improvement will be retarded. My experience has satisfied me that no system of measurement depending on the power of sight is suitable for obtaining the size of the working parts of machines. Where exact size or good fitting is required, the sense of touch is far more to be depended upon. I make standards of size by a system of measurement depending for its accuracy upon the sense of touch; and use an instrument provided with a mechanical multiplier, by which a space is presented to the eye many thousand times greater in extent than is the case where the distance is directly measured by sight only.

With truth of surface, that never-failing element of success, as the basis of operation, we are enabled to measure with exactitude; and there is no difficulty in making parts of machines to fit one another with any degree of nicety: but, when we wish to express correctly by the common fractional system very minute measurements, our ideas are cramped and bampered by an inconvenient and often confused system of notation. What exact notion can any man have of such a size as "a bare sixteenth" or "a full thirty-second"; and what inconvenient results may ensue from the different notions of different workmen as to the value of these terms. A scale of notation that may have suited the old system of manufacture has been left behind, I am happy to say, as the present age has improved on the past; and our improvement has created a want which necessity urges us to 
supply without delay. In the production of duplicate parts of machinery, correct measurement is indispensable to ensure good work : and if, as is the case, we are able to measure with all the accuracy and nicety that can be required, we surely ought at once to adopt a system of notation which will properly represent our measurements.

As an illustration of the importance of very small differences of size, I have brought an internal gauge having a cylindrical aperture 5770 inch diameter, and two external gauges or solid cylinders, one being 5769 inch and the other 5770 inch diameter. The latter is $1-10,000$ th of an inch larger than the former, and fits tightly in the internal gauge when both are clean and dry; while the smaller 5769 inch gauge is so loose in it as to appear not to fit at all. These gauges are finished with great care, and are made true after being casehardened. They are so hard that nothing but the diamond will cut them, except the grinding process to which they have been subjected. The effect of applying a drop of fine oil to the surfaces of these gauges is very remarkable. It will be observed that the fit of the larger cylinder becomes more easy, while that of the smaller becomes more tight. These results show the necessity of proper lubrication. In the case of the external gauge 5770 inch diameter, the external and internal gauges are so near in size that the one does not go through the other when dry, and if pressed in, there would be danger of the surface particles of the one becoming imbedded in or among those of the other, which $\mathrm{I}$ have seen happen, and then no amount of force will separate them : but with a small quantity of oil on their surfaces, they move easily and smoothly. In the case of the external gauge $\cdot 5769$ inch diameter, which is $1-10,000$ th of an inch smaller in diameter than the internal gauge, a space of half that quantity is left between the surfaces; this becomes filled with the oil, and hence the tighter fitting which is experienced.

It is therefore obvious both to the eye and the touch, that the difference between these two cylinders of 1-10,000th of an inch is an appreciable and important quantity; and what is now required is a method which shall express systematically and without confusion a scale applicable to such minute differences and measurements : it should be based on a uniform principle which will accustom the workman to speak of his measures as aggregates of very small differences; and when a good workman becomes familiar with such sizes as $1-1,000$ th and 1-10,000th of an inch, he will 
not rest satisfied until he can work with corresponding accuracy. He will also be able to judge of their effect under different circumstances, and know how much to allow in the fitting parts of a machine, according to their relative importance and the treatment they are likely to receive at the hands of the attendant. For instance, the eylinder of the moving headstock of a lathe requires as good a fit as possible; but in practice it is found that the cylinder must be $\cdot 0005$ inch or 1-2000th of an inch too small, because it frequently happens that machinery is not kept in a proper state of cleanliness, or from motives of false economy is lubricated with bad oil. These are two evils which are productive of great mischief. The abrasion caused by accumulated dust and grit produces increased wear and tear, and soon injures the surfaces in contact; while bad oil becomes sticky and rancid, and spoils the working of a good fit.

And here let me state what I think is the proper definition of a good fit. A tight fit is not necessarily a good one; but when the surfaces are true, and a proper allowance is made in the size of the parts working together, then a good fit is obtained. What constitutes a proper allowance or difference in size depends on the nature of the case, and the treatment which the machinery will meet with. In machinery supplied to establishments using rape oil there must be greater allowance and looseness in the fits than would be requisite if better oil, as sperm oil, were used. I need scarcely say how much more advisable it is to have the more accurate fit and use the best oil, than to have a loose fit and use the inferior oil which causing more friction consumes greater power.

Again, a good workman acquires by experience an intuitive knowledge of the allowances in size which are requisite in various cases; and if a suitable decimal system of notation be adopted, there will be no difficulty, with the power of measurement we now possess, in registering minute differences; and so the knowledge gained by the experienced workman may be imparted to others in precise terms, which to the young beginner will be of invaluable service. Much important information may by these means be stored up, and at any time reference can be made to the experience of the past, which will then run no risk of being lost through disuse, inattention, or other causes.

The deterioration of templates or patterns of size, from their becoming worn or altered in process of time, is productive of great inconvenience, as many of us perhaps have experienced. For when an original standard was 
thus altered, it was irretrievably lost, because there were no means of ascertaining and recording the exact measure. It is of great importance to the manufacturer who makes parts of machines in large quantities to have the means of referring to an accurate fixed measure: it will enable him to reproduce at any time a facsimile of what he has once made, and so preserve a system of sizes of the fitting parts unaltered. The greatest care should be taken to make standards of size correctly at first, and to preserve them unaltered. Errors in the standards are not only propagated in the copies, but are superadded to the errors in the workmanship, which will occur in the course of manufacture; and this is especially likely to oceur in cases where one manufacturer supplies parts of machines for the use of another.

My argument is shortly this:- If we had a better system of notation for our measures, in which small differences in size were expressed in terms conveying their value to the mind, the importance of minute and accurate measurements would become more familiar, more appreciated, and more generally applied. Many operations would by that means be more easily and effectually performed, and in some cases greater safety will be the result. Take for instance the present method of proving guns, which are proved by firing them with a considerable charge of powder and shot. If the barrel stands the proof without manifest injury, it is passed as a good one, while it may in the very process of proof have received such permanent injury as to render it highly dangerous for use. How much better it would be after proving the barrel to measure it, and ascertain accurately if any, and what, * permanent alteration had taken place, and retain or reject it accordingly. This would be substituting an exact and satisfactory system for an uncertain and dubious trial; but, inasmuch as the degrees of alteration will be various, and the differences in their measurement very minute, a better system of notation with the improved mode of measuring is required, to enable this and other similarly useful applications to be made.

After careful thought and a comparison of different scales, I have come to the conclusion that the scale for Standards of Size given in the accompanying Table is the one I would recommend to be adopted. I have endeavoured to arrange one which would be ensily intelligible to the ordinary workman, and that would in every possible case coincide with the old system, so as not to cause more expense in altering the present sizes 
than may be absolutely necessary. I am perfectly aware that other scales may be devised more complete and more advantageous in many respects, if we were now prepared not merely to revolutionise but to abandon what has been manufactured and is now in use. But would not that be going too far? As long as the machines already made are in existence, the sizes of their parts cannot be abandoned; and these considerations have induced me to propose a scale which shall combine the greatest possible advantages with the least possible change.

It would be desirable that those establishments which may decide upon adopting the decimal scale should introduce rules having the inch divided into tenths and their subdivisions, which would soon become as familiar to the workman as the eighth scale he now uses.

The scale proposed for the Wire-Gauge commences with the smallest size and increases by thousandths of an inch up to half an inch. Contrary to the custom usually adopted in marking the wire-gauge, I have called the smallest size No. 1, being 1-1000th of an inch, No. 2 being 2-1000ths of an inch, and so on; increasing up to No. 20 by 1-1000th of an inch between each No.; from No. 20 to No. 40 by 2-1000ths; from No. 40 to No. 100 by $5-1000$ ths of an inch. I propose therefore to suppress the use of the numbers of designation which have been hitherto employed for the various wire-gauges, and simply call the sizes by their expressive numbers in thousandths of an inch, as shown in the accompanying Table of Wire-Gauges; a change which will, I think, render the new scale easily intelligible and convenient for use. 
MR. WHITWORTH'S PROPOSED DECIMAL SCALE.

STANDARDS OF SIZE.

WIRE-GAUGE.

\begin{tabular}{|c|c|c|}
\hline \multicolumn{3}{|c|}{$\begin{array}{c}\text { Proposed } \\
\text { Standards of Size } \\
\text { for Taps and Dies. }\end{array}$} \\
\hline $\begin{array}{l}\text { No. of } \\
\text { Sorew } \\
\text { Threads } \\
\text { per } \\
\text { Inch. }\end{array}$ & $\begin{array}{l}\text { old } \\
\text { sizes. }\end{array}$ & $\begin{array}{l}\text { New } \\
\text { Standards } \\
\text { of Size. } \\
\text { Decinals } \\
\text { of an Inch. }\end{array}$ \\
\hline $\begin{array}{l}48 \\
40 \\
32 \\
24 \\
24 \\
24 \\
20 \\
20 \\
18\end{array}$ & $\frac{1}{3}$ & $\begin{array}{l}\cdot 100 \\
\cdot 125 \\
\cdot 150 \\
\cdot-175 \\
\cdot 200 \\
.225 \\
.250 \\
.275 \\
.300\end{array}$ \\
\hline $\begin{array}{l}18 \\
18 \\
16 \\
16 \\
14 \\
14 \\
14 \\
12\end{array}$ & $\frac{3}{8}$ & $\begin{array}{l}325 \\
-350 \\
-375 \\
-400 \\
-425 \\
-450 \\
+475 \\
.500\end{array}$ \\
\hline $\begin{array}{l}12 \\
12 \\
12 \\
12 \\
11 \\
11 \\
11 \\
11\end{array}$ & $\frac{5}{8}$ & $\begin{array}{l}\cdot 525 \\
\cdot 550 \\
\cdot 575 \\
\cdot 600 \\
.625 \\
.650 \\
.675 \\
\cdot 700\end{array}$ \\
\hline
\end{tabular}

\begin{tabular}{|c|c|c|c|c|c|c|}
\hline \multicolumn{2}{|c|}{$\begin{array}{l}\text { Proposed } \\
\text { Standard } \\
\text { Wire-Garge. }\end{array}$} & $\begin{array}{c}\text { Old } \\
\text { Birmingham } \\
\text { Wire-Gauge. }\end{array}$ & $\begin{array}{c}\text { Old } \\
\text { Lancashire } \\
\text { Wixe-Gauge. }\end{array}$ & $\begin{array}{c}\text { old } \\
\text { Metal or } \\
\text { Plate-Gauge. }\end{array}$ & $\begin{array}{c}\text { Old } \\
\text { Needle } \\
\text { Wire-Gauge. }\end{array}$ & $\begin{array}{c}\text { Old } \\
\text { Music } \\
\text { Wire-Gauge. }\end{array}$ \\
\hline $\begin{array}{c}\text { Value of } \\
\text { each No. } \\
\text { in } \\
\text { Decimals } \\
\text { of an } \\
\text { Inch. }\end{array}$ & $\begin{array}{l}\text { New Nos. } \\
\text { of Gauge. } \\
\text { Thousandths } \\
\text { of an Inch. }\end{array}$ & $\begin{array}{c}\text { old Nos. } \\
\text { of } \\
\text { Gauge } \\
\text { corresponding } \\
\text { to } \\
\text { New Nos. }\end{array}$ & $\begin{array}{c}\text { old Nos. } \\
\text { of } \\
\text { Gauge } \\
\text { corresponding } \\
\text { to } \\
\text { New Nos. }\end{array}$ & \begin{tabular}{|c|} 
old Nos. \\
of \\
Gauge \\
corresponding \\
to \\
New Nos.
\end{tabular} & \begin{tabular}{|c|} 
Old Nos. \\
of \\
Gauge \\
corresponding \\
to \\
New Nos.
\end{tabular} & $\begin{array}{l}\text { Old Nos. } \\
\text { of } \\
\text { Gauge } \\
\text { corresponding } \\
\text { to } \\
\text { New Nos. }\end{array}$ \\
\hline $\begin{array}{l}.001 \\
.002 \\
.003 \\
.004 \\
.005 \\
.006 \\
.007 \\
.008 \\
.009 \\
.010\end{array}$ & $\begin{array}{r}1 \\
2 \\
3 \\
4 \\
5 \\
5 \\
6 \\
7 \\
8 \\
9 \\
90\end{array}$ & $\begin{array}{l}34 \\
33 \\
32 \\
31\end{array}$ & & $\begin{array}{l}1 \\
2 \\
\cdots \\
\dddot{3}\end{array}$ & $\begin{array}{l}17 \\
16 \\
15 \\
14\end{array}$ & \\
\hline $\begin{array}{l}011 \\
.012 \\
.013 \\
.014 \\
-015 \\
.016 \\
.017 \\
.018 \\
.019 \\
.020\end{array}$ & $\begin{array}{l}11 \\
12 \\
13 \\
14 \\
15 \\
16 \\
17 \\
18 \\
19 \\
20\end{array}$ & $\begin{array}{l}30 \\
29 \\
28 \\
\dddot{27} \\
\dddot{26}\end{array}$ & $\begin{array}{l}\cdots \\
\dddot{80} \\
79 \\
78 \\
77 \\
\dddot{76} \\
75\end{array}$ & $\begin{array}{c}\dddot{5} \\
6 \\
\dddot{6} \\
\dddot{7} \\
8 \\
\cdots \\
\cdots \\
\dddot{9}\end{array}$ & $\begin{array}{l}13 \\
12 \\
11 \\
\dddot{10}\end{array}$ & $\begin{array}{l}6 \\
7 \\
8\end{array}$ \\
\hline $\begin{array}{l}.022 \\
.024 \\
.026 \\
.028 \\
.030 \\
\end{array}$ & $\begin{array}{l}22 \\
24 \\
26 \\
28 \\
30 \\
\end{array}$ & $\begin{array}{l}244 \\
23 \\
\dddot{22} \\
\ldots\end{array}$ & $\begin{array}{l}74 \\
72 \\
71 \\
70 \\
68 \\
\end{array}$ & $\begin{array}{l}\text { iö } \\
\dddot{11} \\
\ldots\end{array}$ & $\begin{array}{c}7 \\
6 \\
\dddot{5} \\
\ldots\end{array}$ & $\begin{array}{l}10 \\
12 \\
13 \\
14 \\
15\end{array}$ \\
\hline
\end{tabular}




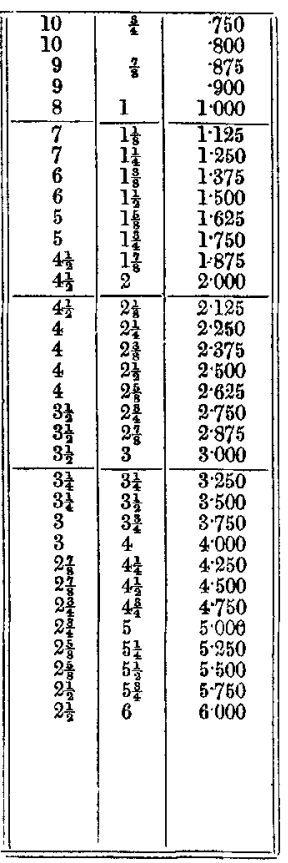

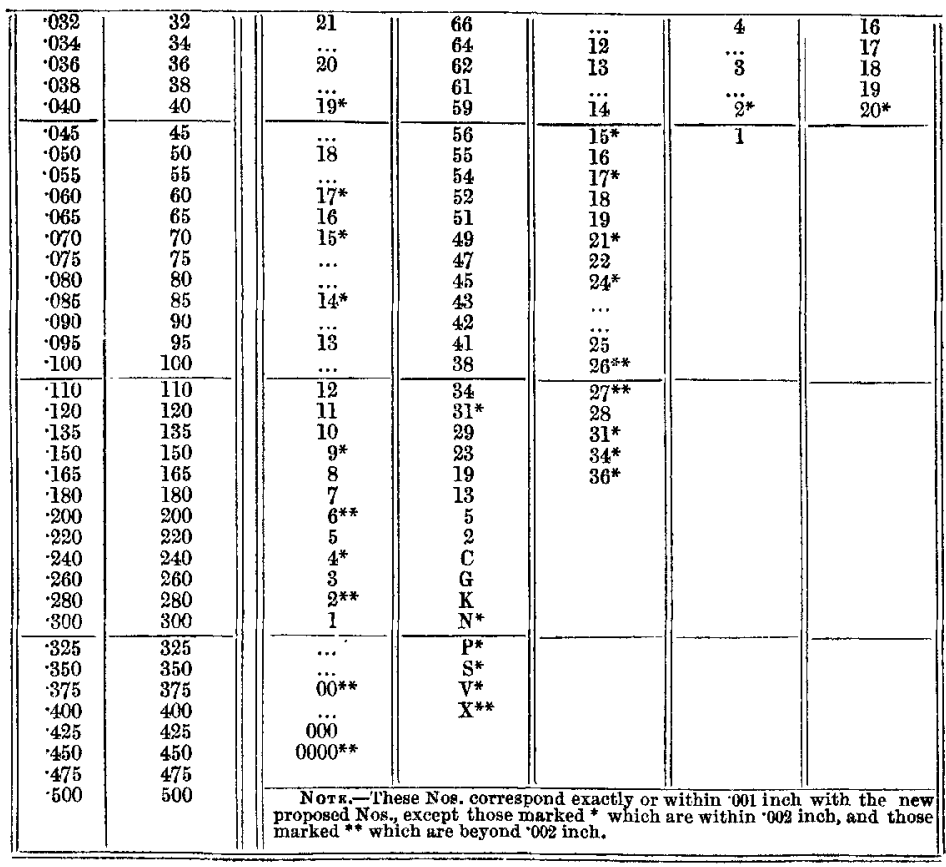


The Chatrman exhibited a cylindrical gauge of the standard size for the bore of the Government rifles 5770 inch diameter, and showed that when dry it fitted tight into the internal gauge of the same size, and that another cylinder 5768 inch diameter or $\cdot 0002$ inch smaller was quite loose in the same internal gauge, showing that so small a dimension was readily appreciable. On adding a small drop of oil the larger cylinder passed freely through the gauge, but the smaller one fitted tighter than before.

Mr. DYER enquired what was considered the explanation of the apparently contradictory change produced by the oil in the two cases : he supposed that in the first case the particles in the two pieces of metal being quite clean were in such intimate contact as to bring the actual cohesion of the particles into effect, preventing the motion of one surface over the other; but that when lubricated the minute interstices of the surfaces were filled up level with oil, preventing the particles of metal from coming into such complete contact and allowing the one surface to slide over the other.

The Chalmman thought that the action was no doubt of that nature; when the surfaces of the two pieces were quite clean, if the one was forced into the other the surfaces seized and set absolutely fast, but the particles of oil enabled the one piece to make its way into the aperture of the other.

Mr. Fatrbairn observed that the question of a decimal system of measure that had been urged in Mr. Whitworth's paper was one of very great importance, affecting all the workshops of the kingdom; and he felt no doubt that if the excellent suggestions of the paper were adopted, it would greatly increase the exactness of work. The accuracy of measurement by the present system was certainly not equal now to the accuracy attainable in workmanship. In steam engine work and particularly locomotive work the true system was for all corresponding parts to be perfect duplicates, and this could be thoroughly carried out only by great certainty and accuracy in measurement. He considered the country was much indebted to Mr. Whitworth for having brought the subject forward in this practical manner, after having afforded them such lasting aid in obtaining accuracy of work. He had no doubt that if a number of employers of mechanics were to start the adoption of the proposed decimal system of measurement, it would be generally carried out, as the advantages were so decided that it only required the first difficulties of actual carrying out to be got over, and the sooner that start was made the better. 
Mr. MoConnele considered the subject a very important one, and felt quite satisfied of the desirability and importance of carrying it out at once. In the present system of measure the bare 1-16th and full 1-32nd were highly unsatisfactory, and mistakes and expense were caused by their indefiniteness and by the various ways of understanding them. The practice of expressing dimensions in feet, inches, and a variety of fractions, was troublesome and complicated, and he had no hesitation in approving a single decimal system as the best mode of removing the objections; he thought they must undoubtedly take the inch as the unit, and that any other would be impracticable for mechanical work generally. It would of course have been highly desirable if the French decimal measure and our own could be amalgamated, as had been often suggested; but he was satisfied that any attempt to change the English measures entirely by substituting another standard, such as the French metre, would be quite impracticable, and would result merely in postponing the whole question indefinitely. The only course now open was to make the best of the present circumstances, and he quite agreed that the inch was the best standard for the purpose, as the most intimately connected with mechanical work generally, and the only one that would not involve any alteration in the value of the other measures now used. He was quite satisfied that $\mathrm{Mr}$. Whitworth's proposal was the best practical solution of the question, and that a combined movement made by mechanical men would ensure its adoption; he knew of many already who were ready to adopt it, and only required the start to be made.

Sir C. Fox fully agreed with the system proposed in Mr. Whitworth's paper, and was much pleased that the proposal had been made; the general adoption of a decimal system of measure was a great desideratum for all mechanical work, to take the place of the present imperfect and confused system, and he fully agreed with the proposal as the best way of accomplishing the object. He considered the question of the actual unit to be adopted was not practically of so much consequence as might be supposed at first; the great point was to agree upon the unit and then to stick to it. He believed it was totally impracticable in this country to change the inch, that being identified with all mechanical work; and the inch being involved in all the other existing measures was the best to be adopted as the single unit on which to base the decimal system of measure. The comparison with the decimal system of any other country, such as the French metre 
system, would then become easy, as a single multiplier would then translate every measure of the one country into the measure of the other. It wonld then be required to refer to only one figure for the measures of any country; and in the case of the French metre which was so extensively adopted on the Continent, he might mention, as more convenient to remember than the decimal multiplier, that the metre was represented with great accuracy by three ordinary English measures-3 feet, 3 inches, and 3 eighths. Also in calculating the weight of wrought iron, a bar 1 inch square weighed 3.33 lbs. per foot length very nearly; and the sectional area in square inches multiplied by 10 gave the weight in lbs. per yard length. In adopting the decimal system he thought they must be content with the present inch as practically the most convenient unit; dimensions in inehes could be readily brought into feet or yards if required, but a foot or yard decimally divided would be impracticable in relation to inches. The present national standard yard would still serve, being considered- as 36 inches, and this was already verified by reference to the length of a seconds pendulum expressed in inches; the standard itself, of which he lad seen one of the originals at the Royal Astronomical Society, was a gun metal bar about an inch square and a little over 4 feet long, having engraved upon it one yard, and one foot in addition divided into inches. In reference to the French standard, the metre, it was a curious circumstance that, instead of being as was originally intended the 1-10,000th part of one degree of latitude measured at Paris, it was now found to be incorrect to a small extent from the results of more accurate recent measurement.

Mr. McConvell suggested that, after the discussion of the question by the meeting, it was advisable that the present meeting be made a starting point for carrying out the proposed system; and that a first step be taken by passing a resolution expressing their approval of the proposed decimal system of measure, and engaging to unite in bringing it into general use.

Mr. Crampton concurred heartily in this suggestion; he thought the proposed change was very desirable, and the question was one that should be taken up and settled by mechanieal men. Mr. Whitworth's proposal was not professed to be absolutely perfect, but he quite ngreed that it was the best practical solution of the difficulty. Some little sacrifice and inconvenience was of course inevitable in such a change; but in the proposed system the difficulties were reduced to so small an amount, by 
taking advantage of so many existing sizes to be retained in the decimal system, that its adoption when once fairly started would be much easier and simpler to effect than might at first appear probable. He thought the Institution of Mechanical Engineers should form a Committee for the purpose of fully investigating the question and carrying out the application of the system, and that all the Members should do their best to aid in advaneing so desirable an object.

Mr. Henry Maudslay considered it very desirable to refer the question to a Committee, that the whole subject might be fully investigated; and thought it would be preferable for this Committee to have the opportunity of considering the subject maturely and collecting information and suggestions as widely as possible, to report to the next Meeting of the Institution, before any resolution was passed upon the subject. He thought the subject was one of great importance to the mechanical world, and they were greatly indebted to the President of the Institution for the consideration he had given to it, and the proposition he had made for carrying it out; the principle of decimal measure was one that he fully agreed with, and it was only in reference to the details and mode of adoption that he thought a longer consideration was advisable before taking any definite step towards carrying it out.

The Chainman observed that the decimal scales he had proposed were really the same as those now existing, both for standards of size and for the wire gauge, excepting a few of the less important sizes, 16ths and 32nds, which he proposed to replace by others agreeing better with a decimal scale; so that in effect the only change proposed was to express all dimensions by a uniform decimal scale of 1000ths of an inch, instead of the present complicated and uncertain system of 8ths, 16ths, and 32nds, and the various wire gauges for smaller dimensions. By this means the exact value of all the present 8ths was retained, on account of the expense and inconvenience that would be involved in abandoning all the present taps and dies, \&.c., of those sizes, besides the great difficulty and indeed practical impossibility of effecting such a change. This was of course not a perfect system ; but he was convinced after several years' consideration of the subject that there was, no chance of getting a more perfect one introduced, and any such proposal would simply result in doing nothing. The great object was to get the decimal system of measure recognised and introduced; when once got into general use its advantages would naturally 
lead to further simplifying the scale and gradually dropping the more complicated decimals.

The proposed decimal wire gauge was a more perfect proposition, as the case was a much simpler one; all the existing sizes of the various gauges could be represented by a scale of 1000ths of an inch, and it was therefore proposed simply to call each size by its real value in 1000 ths of an inch. For example, the present No. 16 wire gauge gave no idea by its name of the actual dimension spoken of ; but the name proposed to be substituted, No. 65, showed at once it was 65-1000ths of an inch, or $6 \frac{1}{2}-100$ ths : and the two tables being both expressed in 1000ths of an inch, the wire gauge became at once a part of the same series of dimensions as the standards of size for taps, \&c., instead of being an entirely unconnected and incommensurable scale. In the proposed scale most of the present sizes were exactly retained, some others being slightly altered in amount to bring them into a more regular progression of sizes than the present scale, which had irregular intervals at some parts. The want of a definite value expressed by each size of the wire gauge led to an extensive and serious evil, for the gauges in use varied materially both in original construction and also from the unavoidable effects of wear; there was thus no definite standard of appeal, so that serious difficulties arose in manufactures from the discrepancies between the gauges used by different parties; and the uncertainty was so great that in the smaller sizes it was customary to send patterns of the thickness required, instead of trusting to the No. of the gauge.

Mr. DYer considered the question of a decimal system of measure a very important one, and one very desirable to be settled and carried into effect at once; he thought this would be best done by mechanical men undertaking to work it out, and they cculd not have a more appropriate opportunity for starting it than the present meeting in Manchester of the Institution of Mechanical Engireers. The advantages of a uniform system of decimal measurement would be very great throughout all their mechanical works and manufactures. As to the standard to be adopted, it did not appear to him at all a serious objection that different nations could not agree to adopt the same standard; the English standard and the French metre were both already in extensive use throughout the world, and might so continue, and the comparison between the two sets of dimensions would be readily male when both were decimally divided; it should be also 
observed that both standards were in fact of an arbitary nature, being metallic rods carefully preserved for reference in government offices, and each of them legal measures without reference to the supposed natural relation of the French metre to an arc of the meridian.

Sir C. Fox thought it was important that the opportunity of that meeting should be taken to agree upon a resolution as a first step towards carrying out the desired object, the members and visitors present pledging themselves to the adoption of a decimal system of measure, and fixing upon the inch as the unit of measure to be divided decimally into 1000 parts.

Mr. McConnelu cordially supported the proposal; he was quite ready to adopt the decimal system proposed by the President, and thought the present meeting was certainly the right occasion for taking the first step towards carrying it out.

Mr. FaIrbairn thought the proposal should be adopted at once, and considered it the best step that could be taken to adrance the object.

Colonel KENNEDY had long thought the subject a very desirable one to be carried out, and was much pleased that it had been now taken up by

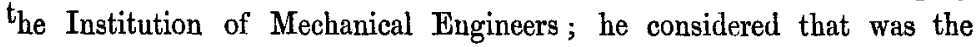
most effective way of obtaining a definite practical result, and hoped the present meeting would decide upon the adoption of the decimal system of measure, and provide for working it out at once by means of a Committee.

Mr. CLIFT was confident that the advantages of the proposed decimal system would be found so great, that it was only necessary to make a start and to have rules made divided decimally, in order to get the system at once introduced into workshops; he had no doubt that its adoption would be found less difficult to effect than might at first seem probable.

Mr. Aston thought it was decidedly the best course on the present occasion to determine on the adoption of the general principle of decimal measure founded on the inch as the unit, as it was clear that that course would completely answer the present purpose, and admit of the system being carried into practice, when the details had been further worked out by a Committee.

Professor Rankine fully agreed in the proposal; he considered it would be a very useful and desirable change to drop the present fractional measures in all mechanical work, and he was ready to adopt the decimal system at once in figuring mechanical drawings, where the use of ordinary fractions was undoubtedly inconvenient and more liable to cause errors. 
Mr. I. Dodps had long felt the great inconvenience of the common fractional dimensions; the bare and full 16 ths were very objectionable and imperfect, though used so frequently in mechanical work; and there would be undoubtedly an important advantage in accuracy and convenience from the adoption of the proposed decimal system of measure.

The following resolution was then passed:- "That this meeting pledge themselves to the adoption of the decimal scale, the inch being divided into 1000 parts."

'The following Paper, by Mr. Charles Fay, of Manchester, was then read :- 